\title{
Integrating HIV prevention and care into maternal and child health care settings: Lessons learned from Horizons studies
}

\author{
Naomi Rutenberg \\ Population Council \\ Sam Kalibala \\ Population Council \\ Charles Mwai \\ James Rosen
}

Follow this and additional works at: https://knowledgecommons.popcouncil.org/departments_sbsr-hiv

Part of the Diseases Commons, and the International Public Health Commons

How does access to this work benefit you? Let us know!

\section{Recommended Citation}

Rutenberg, Naomi, Sam Kalibala, Charles Mwai, and James Rosen. 2002. "Integrating HIV prevention and care into maternal and child health care settings: Lessons learned from Horizons studies," Horizons Report. Washington, DC: Population Council. 


\title{
Hgrizons
}

Integrating HIV Prevention and Care into Maternal and Child Health Care Settings: Lessons Learned from Horizons Studies

\author{
July 23-27, 2001 \\ Maasai Mara and Nairobi, Kenya \\ Consultation Report
}

Horizons Program

Published in 2002 


\title{
Integrating HIV Prevention and Care into Maternal and Child Health Care Settings: Lessons Learned from Horizons Studies
}

\author{
July 23-27, 2001 \\ Maasai Mara and Nairobi, Kenya
}

Consultation Report 


\section{Acknowledgments}

This report was written by Naomi Rutenberg, Sam Kalibala, Charles Mwai, (Horizons/Population Council), and Jim Rosen (independent consultant). Special thanks to representatives from NARESA and the Kenya PMCT sites, the MTCT-Working Group (Zambia), the Monze District Health Management Team (Zambia), the Ndola District Health Management Team (Zambia), the AIDS Information Centre (Uganda), the Ministry of Health (Uganda), Muhimbili Medical Center (Tanzania), the Centre for Population Studies of the University of Zimbabwe, YRG Care (India), and Population Council/Thailand. Their presentations and lively discussions form the basis for this report. Additionally, we would like to acknowledge Norah Omenda (Population Council/Kenya), who organized workshop and related meeting logistics, and Mike Shambu (Population Council/Kenya) for assistance at the meeting.

USAID This study was supported by the Horizons Program. Horizons is funded by the Global Bureau of Health/HIV-AIDS, U.S. Agency for International Development, under the terms of Award No. HRN-A-00-97-00012-00. The opinions expressed herein are those of the authors and do not necessarily reflect the views of the U.S. Agency for International Development.

Published in February 2002.

\section{Population Council}

The Population Council is an international, nonprofit, nongovernmental institution that seeks to improve the wellbeing and reproductive health of current and future generations around the world and to help achieve a humane, equitable, and sustainable balance between people and resources. The Council conducts biomedical, social science, and public health research and helps build research capacities in developing countries. Established in 1952, the Council is governed by an international board of trustees. Its New York headquarters supports a global network of regional and country offices.

Copyright (C) 2002 The Population Council Inc. 


\section{Table of Contents}

\section{Acronyms and Abbreviations}

Executive Summary 1

$\begin{array}{lc}\text { Introduction } & 6\end{array}$

Key Program Components: Experience to Date and Practical Strategies $\quad 10$

$\begin{array}{ll}\text { Training to Improve the Performance of Health Workers } & 10\end{array}$

Motivating Health Workers 11

Supervision of HIV Services and Quality Assurance of HIV Testing 13

$\begin{array}{ll}\text { Antenatal Care for Mothers } & 15\end{array}$

Follow-up Care for HIV-positive Women $\quad 17$

$\begin{array}{ll}\text { Supporting HIV-negative Women in Risk Avoidance } & 18\end{array}$

$\begin{array}{ll}\text { Voluntary Counseling and Testing Services } & 20\end{array}$

Counseling on Infant Feeding $\quad 22$

Antiretrovirals to Reduce Mother-to-Child Transmission 25

$\begin{array}{ll}\text { Involving Male Partners } & 29\end{array}$

$\begin{array}{ll}\text { Conclusion } & 31\end{array}$

Appendixes
A. Agenda
B. List of Participants 36
$\begin{array}{ll}\text { C. References } & 39\end{array}$
D. Operations Research Priorities 40 


\section{Acronyms and Abbreviations}

$\begin{array}{ll}\text { AIC } & \text { AIDS Information Center, Uganda } \\ \text { AIDS } & \text { Acquired Immune Deficiency Syndrome } \\ \text { ANC } & \text { Antenatal care } \\ \text { ARV } & \text { Antiretroviral } \\ \text { AZT } & \text { Zidovudine } \\ \text { DHMT } & \text { District Health Management Team, Zambia } \\ \text { GTZ } & \text { German Development Cooperation } \\ \text { HIV } & \text { Human Immunodeficiency Virus } \\ \text { IMCI } & \text { Integrated Management of Childhood Illness } \\ \text { MCH } & \text { Maternal and child health } \\ \text { MTCT } & \text { Mother-to-child transmission of HIV } \\ \text { MTCT-WG } & \text { MTCT Working Group, Zambia } \\ \text { NACWOLA } & \text { National Community of Women Living with HIV/AIDS, Uganda } \\ \text { NARESA } & \text { Network of AIDS Researchers in East and Southern Africa } \\ \text { NGO } & \text { Nongovernmental organization } \\ \text { PLHA } & \text { People living with HIV/AIDS } \\ \text { PMCT } & \text { Prevention of mother-to-child transmission of HIV } \\ \text { TBA } & \text { Traditional birth attendant } \\ \text { UNAIDS } & \text { United Nations Programme on HIV/AIDS } \\ \text { UNICEF } & \text { United Nations Children's Fund } \\ \text { USAID } & \text { Woluntary counseling and testing for HIV } \\ \text { VCT } & \text { World Health Organization } \\ \text { WHO } & \text { WOFAK }\end{array}$


HIV and MCH Consultation Report

\section{Executive Summary}

Many women in the developing world still lack access to high-quality HIV/AIDS prevention and care services. To address this problem, Horizons has undertaken a range of operations research efforts that examine the integration of HIV-related care in the maternal-child health (MCH) setting. At a workshop held in Kenya in July 2001, participants discussed the experience to date and formulated practical strategies for improving this integration. This report summarizes that discussion according to the following seven key program components.

\section{Training and Motivation to Improve the Performance of Health Workers}

As with any new health service, introduction of HIV prevention and care activities requires training health workers to acquire specific knowledge, skills, and attitudes. At the same time, institutions must create an enabling and supportive environment that motivates workers to effectively apply their learning. Although challenges still remain, programs appear to be adequately training the health workers who provide HIV-related services. Training has increased the number of knowledgeable and capable staff and has had important positive effects on the attitudes of health workers and on reducing stigma toward women infected with HIV.

Nonetheless, project sites are still short on staff with the skills to provide HIV-related care, particularly trained counselors. High rates of staff turnover and lack of training for nonclinical staff continue to hamper program effectiveness. The introduction of services to prevent mother-to-child transmission of HIV has had a mixed impact on motivating health workers in the maternal-andchild health setting. Although many workers are encouraged by finally getting the tools to help clients and their babies fight HIV/AIDS, the extra work can be a disincentive for underpaid, underequipped staff, whose own HIV-related needs are rarely met.

To improve and expand worker performance, workshop participants suggested a number of practical strategies. Further in-service training to increase the number of trained workers and to train replacements, coupled with including prevention of mother-to-child transmission (PMCT) in the curriculums of medical and nursing schools, should broaden the pool of knowledgeable workers. Other strategies include developing job aids such as algorithms for the provider to follow to ensure they provide comprehensive care, flip charts to use during counseling that ensure that all relevant points are covered, posters that prompt the providers to ask certain questions, and evaluation instruments, as well as selectively using technical experts to build staff capacity. To improve worker motivation, programs can take steps to reduce the "turf battles" that demoralize staff, use nonmonetary incentives such as praise and recognition, and work with government officials to address the root causes of motivation problems, including poor working conditions and low pay. 


\section{Hgrizons}

\section{Supervision of HIV Services and Quality Assurance of HIV Testing}

Effective supervision is a key complement to training and other strategies to improve worker performance. Some health systems have begun to integrate supervision of HIV-related programs into routine supervision of $\mathrm{MCH}$ care. However, efforts to standardize such supervision through, for example, the use of checklists, are relatively new and still undergoing testing. Many problems that plague supervision more generally — staff shortages, incomplete records, lack of standardized procedures, and so on-also hamper efforts to supervise HIV-related services such as PMCT. Moreover, because many HIV-related services are new, supervisors often lack adequate information on how key program components are performing. Further complicating supervision efforts is the hybrid nature of HIV-related services, with multiple sources financing and supporting different interventions at the same site. Quality assurance of HIV laboratory testing poses a similar coordination challenge.

Better coordination is a key theme of the strategies suggested for improving supervision and quality assurance. Designating a single facility supervisor to coordinate supervision among PMCT partners, as in the Ndola Demonstration Project in Zambia, aims to improve communication and coordination. Similarly, Zambia has launched a national effort to create a centralized and wellcoordinated system of HIV laboratory support and quality assurance. The development of standardized supervision and monitoring tools, under way in a number of countries including Zimbabwe, is also a high-priority strategy.

\section{Caring for Mothers}

High-quality care for mothers should include antenatal care, follow-up for HIV-positive women, and helping HIV-negative women avoid risk of infection. The introduction of PMCT services has rekindled interest in the importance of high-quality antenatal care, and PMCT programs are broadening access to such care by championing changes in policies, service delivery practices, and resource allocation. PMCT programs have successfully put in place new systems to ensure confidential sharing of HIV status within MCH settings. One area in which progress has been slow is the attempt to integrate HIV education and counseling into routine antenatal care. Meanwhile, sites where PMCT has been introduced continue to face many of the generic problems that afflict antenatal care programs.

For all but a few infected mothers, ongoing therapy with antiretroviral drugs remains unaffordable. However, health systems could meet many of the other health needs of these mothers. Efforts to provide follow-up care for HIV-positive women have focused on forging ties with existing care and support services, such as in Zambia, where $\mathrm{MCH}$ programs refer women to groups that provide help in preventing opportunistic infections and in food supplementation. Nonetheless, referral systems and follow-up efforts for all women-regardless of HIV status-are weak. Another key factor hampering follow-up efforts is the fear of stigmatization that makes many PMCT clients reluctant to disclose their HIV status outside the ANC clinic. For the same reasons, most HIVpositive mothers shun existing support groups for people living with HIV/AIDS. 
Promoting HIV prevention in uninfected mothers is critical because infection rates in the postpartum period are high in many countries. Although many women learn they are infection-free in the $\mathrm{MCH}$ setting, very few programs address their subsequent prevention needs. Because of the way services are currently structured, overworked staff focus on counseling HIV-infected women but have virtually no mechanisms in place to follow up on women who are HIV-negative.

Improving care for mothers calls for a mix of actions at the policy and program levels. To expand overall access to quality care, programs should advocate for free or low-cost antenatal care and require that PMCT donors support all elements of antenatal care. Given the limited resources and expertise available in the public sector, programs need to seek partnerships with outside groups to provide services such as nutritional support for pregnant women and lactating mothers, comprehensive HIV care, and counseling. Programs can also improve care through administrative and structural changes, such as scheduling fewer but higher-quality antenatal visits, providing women with incentives for follow-up appointments, and promoting couple counseling.

\section{Voluntary Counseling and Testing Services}

In the MCH setting, voluntary counseling and testing (VCT) has the potential to reach large numbers of women who may already be infected with HIV or at high risk of becoming infected. Where MCH programs have introduced VCT services, for example, in Kenya and Zambia, the response so far has been overwhelming. Some of the main concerns now are maintaining adequate quality in the face of high demand and reaching underserved women. The popularity of VCT also raises questions about the affordability of routine HIV testing on a mass scale.

Strategies to improve VCT aim to address current shortcomings resulting from the high demand for services. To reduce the burden on clinic staff and supplement the limited interaction clients have with counselors, programs should expand health education efforts in the community and diversify the sources of post-test support and ongoing counseling for mothers. Changes in counseling procedures, such as shifting emphasis from pretest counseling to post-test support, assigning dedicated PMCT counselors, and rotating counseling responsibilities could help reduce waiting time for clients and staff burnout.

\section{Counseling on Infant Feeding}

Stopping the transmission of HIV through breast milk is one of the greatest challenges facing PMCT programs. Early experience from introducing an HIV-related infant feeding component to $\mathrm{MCH}$ care has been promising, although many health workers still struggle to provide good information to mothers on such a new and complex topic. Keeping up with the latest, evolving guidelines and not letting their own biases get in the way of providing balanced information are key to helping mothers to make informed decisions. Success in persuading HIV-positive mothers to 


\section{Hgrizons}

accept replacement feeding has been limited, with mothers often rejecting the practice for practical reasons or out of fear of stigmatization.

Strategies for improving infant feeding counseling center on strengthening the counseling interaction. Giving clearer guidance on feeding practices can reduce confusion among both counselors and their clients. Increasing counseling skills training and enhancing the relevance of counseling sessions by documenting how mothers successfully handle difficult feeding situations are also thought to be crucial. Programs should encourage weaning practices that are agreeable to the mother and baby and that continue to effectively prevent transmission of the virus through the breast milk.

\section{Provision of Antiretroviral Drugs to Reduce Mother-to-Child Transmission}

Various antiretroviral (ARV) drug regimens have been proven to significantly decrease the motherto-infant transmission rate. PMCT programs have used a combination of approaches, including the AZT short course and nevirapine. Most plans for scaling up PMCT services propose using the latter drug, primarily because of its relatively low cost and ease of administration. Although PMCT programs still have little experience with ARVs, stigma and misconceptions about the drugs have emerged as important obstacles to acceptance and effective use. With limited success, PMCT programs have made special efforts to help women adhere to the often difficult-to-follow ARV treatment regimens. Because they do not provide mothers with ongoing ARV treatment, PMCT programs are often criticized.

To combat stigma and misinformation, programs need to help communities view ARV treatment for PMCT and other HIV-related services as a routine part of antenatal care. Programs can also encourage ARV use for PMCT and counter criticism about lack of ARV therapy for mothers by stressing the range of benefits that programs are able to offer mothers. Other strategies include fine-tuning clinic procedures to encourage greater adherence to ARV regimens, for example, by starting treatment slightly earlier in the pregnancy.

\section{Involving Male Partners}

Pregnancy and the antenatal care setting can provide a window of opportunity to involve men more deeply in the care of their partners and children. Such involvement is important not only as a means to a healthy pregnancy but also as a way to improve reproductive and sexual health. Efforts to involve men in HIV-related care have been promising, but many gaps still exist. The MCH environment is still largely "unfriendly" to men, many of whom see few concrete benefits from "male involvement." Such attitudes are closely related to deeply ingrained community norms that limit men's involvement in pregnancy care. Moreover, for some women, male involvement is not always desirable. 
Strategies to increase male involvement aim to engage men both in direct ways and via the communities that shape their beliefs and behaviors. For example, a program in Zimbabwe targets grandparents, in-laws, and young people to make male involvement in matters of pregnancy a sustainable community norm. Giving information on PMCT directly to men, appealing to their specific interests to make couple counseling more enticing, and teaching women how to talk to their male partners about HIV are other strategies.

\section{Conclusion}

Overall, success in integrating elements of HIV-related care into the MCH setting has been mixed, and many challenges remain before such care becomes routine. The shortcomings of health systems, pervasive stigma attached to HIV-infected women, and varied nature of HIV-related services all present difficult obstacles. Strategies to overcome these barriers include working to make HIV-related care the norm in the MCH setting; drawing on resources and expertise outside the clinic; making incremental, low-cost changes; and, over the long term, advocating for policies and increased funding to support integration efforts. More information on program costs and effectiveness can help managers make informed decisions about how to invest resources to ensure that women everywhere get the best care possible. 


\section{Hgrizons}

\section{Introduction}

Two decades after the emergence of the HIV/AIDS pandemic, most women in developing countries are not reached by effective prevention and care interventions because of limited service delivery as well as socioeconomic and gender-related barriers that impede access to existing services. MCH care settings may offer women and their families an important entry point to critical services because of their widespread availability and community acceptance. Moreover many women make repeated visits for antenatal, postpartum, and infant care, thus increasing their potential access to vital HIV/AIDS services that focus on primary prevention, vertical transmission, and care and support of those infected.

This report documents lessons learned from Horizons intervention studies that focus on integrating HIV prevention and care activities into MCH settings. Horizons is a USAIDfunded operations research program aimed at refining HIV/AIDS prevention, care, and support efforts. Horizons identifies problems in service delivery, tests new approaches, and disseminates the research findings to program managers and policymakers to foster improved policy and program development.

The information contained in this report emerged from a three-day consultation in Maasai Mara, Kenya, July 23-25, 2001, that brought together study investigators and service managers, including district medical officers and nurses in charge of individual clinics. Participants represented studies that focus on a broad range of topics related to the delivery of HIV prevention and care in the $\mathrm{MCH}$ setting (see Table 1), including prevention of mother-to-child transmission (PMCT), HIV counseling and testing, male involvement in antenatal care (ANC), and partner violence. The Horizons studies that are discussed in this report focus on either integrating HIV/AIDS activities into key

\section{Box 1 Mother and child health care}

$\mathrm{MCH}$ care encompasses a broad range of information and services that help mothers and their children lead healthy lives:

- Nutrition for mothers and children (iron folate supplementation, vitamin A supplementation; eating correctly during pregnancy).

- Immunization for mothers (tetanus toxoid).

- Antenatal care for women.

- Treatment of pregnant women for malaria.

- Helping women and families prepare for a healthy birth.

- Birthing care.

- Promotion of breastfeeding and infant nutrition.

- Control of diarrheal disease in children.

- Immunization for children.

- Detection and treatment of acute respiratory infections in children.

- Growth monitoring.

- Family planning.

Mother and child health care settings and the types of health workers that provide such care are diverse. In both public and private sector services, $\mathrm{MCH}$ care may be provided at fixed sites such as hospitals, health centers, clinics and posts, as well as through community-based services that may operate out of multiple locations. Similarly, the types of health worker that provide $\mathrm{MCH}$ care can vary enormously, ranging from highly trained medical specialists to community volunteers and even familv members 
services that make up the continuum of care for women, including family planning, ANC and delivery, and postnatal care; or on making voluntary counseling and testing (VCT) services more responsive to the needs of adolescent and adult women.

Table 1 Horizons studies represented at the consultation

\begin{tabular}{|c|c|c|c|}
\hline Study Title & Country & Partners & References \\
\hline $\begin{array}{l}\text { Prevention of } \\
\text { Mother-to-Child } \\
\text { Transmission of HIV }\end{array}$ & $\begin{array}{l}\text { Kenya } \\
\text { and } \\
\text { Zambia }\end{array}$ & $\begin{array}{l}\text { NARESA, NASCOP } \\
\text { Kenya, Kenya MOH, } \\
\text { Zambia HIV Mother- } \\
\text { to-Child Transmission } \\
\text { Working Group, } \\
\text { UNICEF Kenya and } \\
\text { Zambia }\end{array}$ & $\begin{array}{l}\text { http://www.popcouncil.org/pdfs/ } \\
\text { horizons/rs/re_mtct.pdf } \\
\text { http://www.popcouncil.org/horizons/ } \\
\text { newsletter/horizons(2)_3.html }\end{array}$ \\
\hline $\begin{array}{l}\text { Testing Clinic- and } \\
\text { Community-based } \\
\text { Strategies for PMCT }\end{array}$ & Zambia & $\begin{array}{l}\text { Ndola District Health } \\
\text { Management Team, } \\
\text { Hope Humana, } \\
\text { National Food and } \\
\text { Nutrition Council, } \\
\text { Linkages Project, } \\
\text { Zambia Integrated } \\
\text { Health Project }\end{array}$ & $\begin{array}{l}\text { http://www.popcouncil.org/pdfs/ } \\
\text { horizons/rs/re_mtct.pdf }\end{array}$ \\
\hline $\begin{array}{l}\text { Developing High- } \\
\text { quality VCT Service } \\
\text { Delivery Strategies } \\
\text { for Youth }\end{array}$ & Uganda & $\begin{array}{l}\text { AIDS Information } \\
\text { Centre, Makerere } \\
\text { University }\end{array}$ & $\begin{array}{l}\text { http://www.popcouncil.org/pdfs/ } \\
\text { horizons/vctyouthbaseline.pdf } \\
\text { http://www.popcouncil.org/horizons/ } \\
\text { newsletter/horizons(2)_2.html } \\
\text { http://www.popcouncil.org/horizons/ } \\
\text { ressum/vct_youth.html } \\
\text { http://www.popcouncil.org/pdfs/ } \\
\text { horizons/rs/re_vct.pdf }\end{array}$ \\
\hline $\begin{array}{l}\text { Integrating VCT in } \\
\text { Primary Health Care } \\
\text { Centers }\end{array}$ & Uganda & $\begin{array}{l}\text { AIDS Information } \\
\text { Centre, AIDS Control } \\
\text { Programme, } \\
\text { Makerere Institute of } \\
\text { Social Research } \\
\end{array}$ & $\begin{array}{l}\text { http://www.popcouncil.org/pdfs/ } \\
\text { horizons/rs/re_vct.pdf }\end{array}$ \\
\hline $\begin{array}{l}\text { HIV-associated } \\
\text { Violence: } \\
\text { Implications for VCT } \\
\text { Programs }\end{array}$ & Tanzania & $\begin{array}{l}\text { Muhimbili Medical } \\
\text { Centre }\end{array}$ & $\begin{array}{l}\text { http://www.popcouncil.org/pdfs/ } \\
\text { horizons/vctviolence.pdf } \\
\text { http://www.popcouncil.org/horizons/ } \\
\text { ressum/vct_violence.html } \\
\text { http://www.popcouncil.org/horizons/ } \\
\text { newsletter/horizons(2)_1.html }\end{array}$ \\
\hline $\begin{array}{l}\text { Reducing STI/HIV } \\
\text { Risk among } \\
\text { Pregnant Women } \\
\text { and their Partners }\end{array}$ & Zimbabwe & $\begin{array}{l}\text { University of } \\
\text { Zimbabwe }\end{array}$ & $\begin{array}{l}\text { http://www.popcouncil.org/horizons/ } \\
\text { newsletter/horizons(2)_4.html } \\
\text { http://www.popcouncil.org/pdfs/ } \\
\text { horizons/rs/re_mtct.pdf }\end{array}$ \\
\hline
\end{tabular}




\section{Hgrizons}

During the consultation, each participant presented an overview of his or her study, including objectives, major activities and milestones, and outcome measures. The presentations highlighted what has and has not worked in terms of program feasibility, acceptance, and effectiveness, and recommendations for replication and scale-up. The broad representation of participants enabled the sharing of experiences on such topics as training of health workers, communication strategies, monitoring and evaluation, and service delivery. The focus of discussions ranged from the introduction of specific new HIV services such as VCT and antiretroviral (ARV) prophylaxis to the strengthening of existing routine $\mathrm{MCH}$ services to addressing policy barriers. Critical areas for additional operations research were noted.

The retreat was followed by a one-day meeting in Nairobi on July 27, 2001, to further enrich the workshop discussions with the insights and experiences of agencies supporting or implementing activities to prevent mother-to-child transmission of HIV. In addition to workshop attendees, participating organizations included the Ministry of Health of Kenya, USAID/Kenya, USAID/Uganda, WHO/Uganda, the African Regional Office (AFRO), the East and Southern Africa regional office of UNICEF, German Development Cooperation (GTZ), Médecins sans Frontières, and the U.S. Centers for Disease Control and Prevention (CDC).

The report organizes workshop presentations and discussion around seven key components that all quality programs should incorporate:

- Training and motivation to improve the performance of health workers.

- Supervision and quality assurance.

- Care for the mother, including antenatal care, follow-up for HIV-positive women, and help for HIV-negative women to avoid risk of infection.

- Voluntary HIV counseling and testing.

- Counseling on infant feeding.

- Provision of ARVs to reduce mother-tochild transmission.

- Involvement of male partners.

\section{Box 2 Mother-to-child transmission of HIV}

Worldwide, more than 4 million children are estimated to have died from AIDS, primarily contracted through mother-to-child transmission (MTCT). MTCT is especially widespread in Africa, where approximately 600,000 babies become infected with HIV every year. MTCT can occur during pregnancy, at the time of delivery, or through breastfeeding. Clearly, the best way to prevent MTCT is to prevent HIV infection among women of reproductive age.

However, strategies also exist to help the millions of women already infected to reduce the likelihood of transmitting HIV to their infants. A comprehensive program to prevent mother-to-child transmission (PMCT) includes:

- High-quality antenatal, delivery, and postpartum services.

- Voluntary and confidential counseling and testing services.

- Short-course ARV prophylaxis for HIVinfected pregnant women.

- Counseling and support for safe infant feeding practices.

- Strengthened health, family planning, and safe motherhood programs.

Adapted from: "USAID's Response: Motherto-Child Transmission"

http://www.usaid.gov/pop_health/aids/

TechAreas/mtct/mtctfactsheet.html 
Many countries are currently grappling with the problem of how to initiate, expand, and increase the effectiveness of HIV-related interventions, including VCT and PMCT programs. It is hoped that the lessons learned through the Horizons studies - which are shared in this report-will benefit both the replication and scaling up of HIV programs in the MCH setting. 


\section{Hgrizons}

\section{Key Program Components: Experience to Date and Practical Strategies}

\section{Training to Improve the Performance of Health Workers}

As with any new health service, introduction of HIV prevention and care activities requires training health workers to acquire specific knowledge, skills, and attitudes.

\section{Experience to date}

Programs have successfully trained hundreds of field staff-including nurses, midwives, counselors, obstetricians/gynecologists, lab technicians, and community health workers- to address HIV prevention and care in the MCH setting. In Kenya, NARESA has designed an integrated PMCT curriculum and trained more than 500 providers from six sites, while the MTCT Working Group in Zambia has developed multiple curriculums emphasizing various components of MTCT and trained 259 health workers. Both programs have also trained laboratory health workers in the use of rapid HIV tests. Projects in Zambia and Zimbabwe have trained clinic staff and community health workers in VCT, infant feeding, and couple counseling. In Uganda, the AIDS Information Center and the Ministry of Health have trained more than 200 health workers to provide comprehensive VCT services in primary health care settings.

The training, which includes information on the epidemiology of HIV/AIDS and ways workers can protect themselves from infection on the job, has had important positive effects on the attitudes of health workers and on reducing stigma toward HIV-positive women. Providers have developed a friendlier attitude toward women identified as HIV-positive and spend more time with them. Stigma has also diminished as providers serve more HIV-infected clients and become aware that HIV affects women from all walks of life and that people living with HIV/AIDS deserve support, not blame or isolation. Despite the impressive number of workers trained, however, project sites are still short on staff with the skills to provide HIV-related care, particularly trained counselors. Frequent transfer of trained staff out of $\mathrm{MCH}$ programs exacerbates this shortage.

\section{Practical strategies to improve and expand training}

- Continue in-service training to increase the number of trained staff and to train replacements for those who leave. Refresher training is also needed to update providers and to address knowledge gaps identified during supervisory visits. Managers and nonclinical staff should also receive training that uses a shorter, less technical curriculum.

- Provide health workers with job aids that prompt them on what they need to know. The revised antenatal card in Kenya includes all of the information and counseling topics that staff should address during antenatal care. 
- Follow up trainees and monitor their use of skills. NARESA and the MTCT Working Group use a simple tool that evaluates provider performance at 9 and 18 months after the initial PMCT training.

- Integrate PMCT into the curriculums of medical and nursing schools to ensure that all students receive adequate exposure to PMCT. By including a question on PMCT in its final examinations, the obstetrics and gynecology department of Makerere University Medical School in Uganda has obliged lecturers to cover the topic.

- Employ professional counselors to support and mentor newly trained counselors. The Ndola Demonstration Project uses this approach, taking professional counselors on loan from a counseling NGO until the midwives trained in counseling have gained confidence.

- Build the capacity of institutions to manage resources and plan strategically to fully use the skills of providers trained in PMCT. NARESA's PMCT program in Kenya hired a logistics consultant to help pharmacy staff and storekeepers manage stocks of ARVs, infant formula, and test kits.

- Work with national professional bodies-including influential national associations of doctors, nurses, and midwives - to prepare PMCT training and clinical guidelines with the goal of improving the skills of private practitioners. Training medical practitioners in the private sector will both broaden the pool of qualified providers and educate a group that is important in determining policy and standards of care. In Kenya, the PMCT program partnered with the Kenya Obstetric and Gynecological Society to develop clinical guidelines for PMCT. The National AIDS Council has adopted these guidelines, which have helped to set national standards for PMCT care.

\section{Motivating Health Workers}

The introduction of HIV/AIDS prevention and care into the MCH setting has meant that health workers have been asked to greatly expand their responsibilities and tasks. Rarely has this been accompanied by financial and other types of compensation or the addition of new staff to share the work. Developing strategies for motivating health workers in these setting is thus also important for success.

\section{Experience to date}

The introduction of PMCT services has had a mixed impact on motivating health workers in the $\mathrm{MCH}$ setting. On the one hand, introducing PMCT services has provided extra motivation and empowered clinic staff by giving them, for the first time, tools to help clients and their babies fight HIV. Many staff are putting extra effort into the care they offer their clients, for example, by providing after-hours counseling and support to mothers living with HIV. On the other hand, PMCT interventions - although designed to be part of routine services - create significant additional work for staff already discouraged by long-standing problems such as low pay and inadequate medical supplies. Motivating staff is particularly difficult in larger, urban health facilities, where specialization of services is greater and different departments and cadres of 


\section{Hgrizons}

providers are often reluctant to share or relinquish authority. These "turf battles" can demoralize staff unable to provide the comprehensive package of PMCT care that their training has prepared them for. By contrast, rural providers have small staffs of health workers who make their own treatment and care decisions and thus can adapt the organization of services to respond better to client needs.

Asking health workers to provide HIV care to others when the health system fails to meet their own HIV-related needs is another factor that diminishes worker motivation. Part of the problem is that many infected health workers are in denial about their own HIV status, so they fail to seek appropriate care. But many staff also fear the discrimination that may result when they disclose their HIV status to counselors - who in many cases are also supervisors. One encouraging development in Zambia is that vocal networks of people living with HIV/AIDS are educating the public about discrimination and making it easier for HIV-positive people to demand their rights. Zambian employers are now more fearful of accusations that they have dismissed someone because they are HIV-positive.

Workshop participants noted a number of motivational strategies that their programs have considered but rejected. Financial incentives are not an option in most settings because neither governments nor donors are likely to fund salary increases. Dividing up PMCT responsibilities among providers, for example, by employing dedicated counselors and leaving nurse-midwives to provide clinical care, can have serious drawbacks. A midwife who has a negative attitude toward HIV-positive clients or lacks knowledge about ARVs could undermine all the good work of a counselor. Splitting responsibilities also increases the time clients must spend at the clinic and potentially reduces use of services. A separate meeting with a counselor can also raise a client's anxiety level.

\section{Practical strategies to improve worker motivation}

- Emphasize from the outset that PMCT is part of routine MCH care. At Kenyatta National Hospital, management made it clear to staff that PMCT would become part of routine care and therefore salaries would not be increased. The program motivated staff by providing further training in safe motherhood so that interested and motivated staff could serve as role models.

- Involve senior staff early in the development of PMCT services to expand program "ownership" and reduce concerns about turf protection. Strategic planning can further help to break down the divisions among staff, raise motivation, and solicit ideas from providers themselves on the strategies they feel will improve motivation.

- Use supportive supervision to praise and recognize staff and build skills, while also addressing the HIV needs of providers.

- Work with top Ministry of Health officials to address the root causes of motivation problems, including poor working conditions and low pay. PMCT programs also must educate government officials about appropriate staffing requirements, including the need for counselors, and point out that officials are responsible for addressing staff shortages. 


\section{Supervision of HIV Services and Quality Assurance of HIV Testing}

Effective supervision is a key complement to training and other strategies to improve worker performance. Health programs have long struggled to change the focus of supervision from administration and paperwork to active support and continuous training of field staff and to serving as a conduit for valuable information on program functioning.

\section{Experience to date}

Some health systems have begun to integrate supervision of HIV-related programs into routine supervision of MCH care. For example, staff from the DHMT in Ndola, Zambia, who routinely supervise health centers are now also supervising new infant feeding and PMCT services. The joint approach is more cost-effective and encourages supervisors to view PMCT as an integral part of $\mathrm{MCH}$ care. Efforts to standardize supervision protocols are relatively new and still undergoing testing. Programs in Zambia and Kenya are examining the use of checklists to ensure that supervision is comprehensive and standardized. Specially trained clinicians use the checklists to observe a range of services, including ANC, VCT, delivery, family planning, postnatal care, child immunization, sick child visits, and counseling.

Many of the problems that plague supervision more generally also hamper efforts to supervise HIV-related services such as PMCT. Supervision of PMCT services is largely ad hoc, and there is no way to monitor whether on-site supervisors are performing their tasks. Because of the multiple responsibilities of clinic managers and staff, it is difficult to keep them interested in and focused on PMCT program objectives. Serving clients always takes priority over supervision, and staff shortages leave supervisors with little time to support and oversee staff. Moreover, heavy workloads often prevent health workers from attending staff meetings called to address constraints. Records crucial for supervision are sometimes incomplete because staff are too busy or lack required stationery.

Partly because many HIV-related services are new, supervisors often lack good information on how key program components are performing. For interventions such as VCT, it has been relatively simple for programs to identify a shortlist of easy-to-collect indicators to measure program performance (for example, the number of women receiving pretest counseling and the number of women tested for HIV). For other services, however, this process is much more difficult. For example, to effectively monitor provision of ARV drugs for PMCT, the supervisor needs updated information on the number of women eligible to receive ARVs (those HIV-positive women who have been pregnant for 34 weeks or more at the time of the supervisory visit). This number is hard to compute from clinic records alone. Other key services are simply not being recorded by information systems. Programs generally tally only the number of women whom they supply with infant formula, and do not count the number of women receiving infant feeding counseling. Routine monitoring of the quality of counseling in the clinic setting also remains problematic, and supervisors lack a simple tool that they can use routinely and in conjunction with their other supervisory tasks. 


\section{Hgrizons}

Further complicating supervision efforts is the hybrid nature of HIV-related services. Often, multiple agencies or administrative entities support different interventions at the same site. For example, in Zambia, the Voluntary Counseling and Testing Program provides VCT, the MTCT Working Group provides ARVs and infant formula, and the District Health Management Team dispenses hemoglobin and iron supplements. Each of these agencies must separately account for their resources, and each employs a different evaluation mechanism.

Quality assurance of HIV laboratory testing poses a similar challenge for coordination among multiple supervisory agencies. Typically, no single entity is responsible for all the laboratory needs of PMCT programs. The national public health laboratories oversee laboratories around the country. HIV test kits are provided by either the PMCT secretariat or by the national AIDS program. The quality assurance experts are usually based at a university or research institution. Coordinating support from these different sources is a challenge for on-site laboratory technologists, and has led to numerous problems. Moreover, coordination often requires travel, but most PMCT programs do not budget for lab-related transportation. Delays in sending test kits and results of samples for confirmatory testing are common. The shelves of some sites are packed with expired HIV test kits, while other labs are chronically short of HIV test kits. Most PMCT programs do not budget adequately for laboratory needs, leading to chronic shortages of key materials. Some countries also report a lack of coordination on official HIV testing algorithms for PMCT.

\section{Practical strategies to improve supervision and quality assurance}

- Standardize supervision by adapting and integrating existing supervision checklists. The Horizons Program has a number of checklists for research observation-including one for infant feeding counseling - that programs could adapt for routine use during supervision. Other agencies have similar checklists. For example, WHO and UNICEF have jointly developed a checklist for the Integrated Management of Childhood Illness (IMCI), which programs could adapt for supervision of infant feeding counseling. One way to standardize the use of these checklists and to monitor trends in service quality is for supervisors to observe a predetermined number of counseling sessions every month at each site during each supervisory visit.

- Interact directly with mothers to supervise infant feeding counseling. Supervisors in the Ndola Demonstration Project ask mothers about the information they have received from counselors and, before discharge, require mothers who have chosen formula feeding to demonstrate that they can properly prepare the formula and feed their baby. Projects with research staff who follow up women at their homes are using feedback from these visits as a source of information on the quality of infant feeding counseling.

- Monitor community outreach activities. The ANC male involvement project in Zimbabwe has developed a simple tool for monitoring community outreach activities that other projects could adapt. It includes such information as date, type of activity, type of group, and comments.

- Include supervisors in PMCT training. Because PMCT is new, some designated supervisors who are not front-line providers lack up-to-date knowledge of the topic. By training such supervisors, projects have successfully addressed this gap while also improving the relationship between the supervisors and PMCT providers. 


\section{HIV and MCH Consultation Report}

- Designate a single facility supervisor to coordinate supervision among PMCT partners. For the Ndola Demonstration Project, supervision of PMCT and information collection is conducted through the DHMT, with partner agencies contributing to the improvement of supervision by supporting existing DHMT staff.

- Create a centralized or well-coordinated system of laboratory support and quality assurance. In Zambia, a national HIV testing body is responsible for training and supervising laboratory staff, quality assurance, and improving coordination of key functions such as purchase of test kits. To avoid expiration of overstocked test kits at the service sites, the national group resupplies each site on the basis of real levels of demand, as shown by returns of the previous month. All VCT programs, including the PMCT programs, now operate under the national body.

- Strengthen laboratory systems. Quality assurance of HIV testing should include specimen labeling, logging, and results handling. Reference laboratories should also have quality assurance systems, preferably provided by an external laboratory. PMCT budgets should include support for laboratory training and operational costs, such as transport and consumables.

\section{Antenatal Care for Mothers}

High-quality antenatal care ensures that a pregnant woman enjoys good health and nutrition during and after pregnancy and that the pregnancy culminates in the delivery of a healthy baby. Antenatal care includes good medical, emotional, and nutritional support during pregnancy, advice on safe delivery, and management of pregnancy-related complications.

\section{Experience to date}

The introduction of PMCT services has rekindled interest in the importance of high-quality antenatal care, including low-cost, low-effort actions to reduce mother-to-child transmission. These include preventing and treating sexually transmitted infections and malaria during pregnancy and minimizing invasive procedures and trauma during delivery. PMCT programs are broadening access to high-quality antenatal care by championing improvements in policies, service delivery practices, and resource allocation.

Effective PMCT requires that all health workers caring for a client know her HIV status. PMCT programs have successfully put in place new systems to ensure confidential sharing of HIV status within $\mathrm{MCH}$ settings. In both the Kenya and Zambia programs, workers enter HIV test results using a code on the mother's ANC history card. The records clerk files the card and retrieves it each time the mother visits. In the evenings, after regular clinic hours, staff transfer the cards to the labor room, where labor and delivery workers can easily pull the cards for those mothers giving birth at night. Thus far, the system has worked well, with no reported breach of confidentiality. Another encouraging sign is that PMCT programs have been able to maintain the confidentiality of their clients' HIV status even when traditional birth attendants are involved, as in Keemba, Zambia, where TBAs help HIV-positive mothers take their ARVs during labor. 


\section{Hgrizons}

One area in which progress has been slow is the attempt to integrate HIV education and counseling into routine antenatal care. An evaluation nine months after the introduction of the PMCT program in Kenya found that few clients receive counseling on risk reduction during routine antenatal care. On the plus side, discussion of HIV between women and providers and among women themselves is apparently becoming more common in ANC services at PMCT sites. For example, the director of obstetrics and gynecological services at Kenyatta National Hospital reported that clients became much more interested in information about HIV after the introduction of PMCT services. Further anecdotal evidence suggests that efforts by PMCT programs to foster companionship among clinic clients have helped to gradually reduce stigma.

At the same time, sites where PMCT has been introduced continue to face many of the generic problems affecting ANC programs. Supplies of drugs and other medical necessities are unreliable. Cost-sharing mechanisms that require clients to pay may reduce access, and thus remain controversial. At high-volume clinics, demand for even the most rudimentary services overwhelm providers, and quantity concerns often outweigh quality considerations. Clients and providers fail to place sufficient value on routine tests for syphilis, anemia, and blood type. Many mothers attend ANC irregularly, miss essential services because they do not come frequently enough, or miss services only offered at certain times during pregnancy (for example, malaria prophylaxis). Finally, few programs actively work to improve women's nutrition, and little is known about either the nutritional status of HIV-positive women during pregnancy or the impact of nutritional programs that do exist.

\section{Practical strategies to expand and improve antenatal care}

- Advocate for free antenatal care or implement a waiver system for poor women. In Kenya, the $\mathrm{PMCT}$ program is lobbying the government for free antenatal care, including routine laboratory investigations for syphilis, anemia, and blood type; malaria prophylaxis; and micronutrient supplementation.

- Require that PMCT donors support all elements of antenatal care. In Zambia, the MTCT Working Group obligates any group promoting PMCT to also promote comprehensive antenatal care.

- Seek partnerships to provide nutritional support for pregnant women and lactating mothers. In partnership with the PMCT intervention in Zambia, the World Food Program provides highenergy supplements, cooking oil, beans, sugar, multivitamins, and de-worming treatments for HIV-positive women and their children.

- Modify visit frequency protocols. Although programs should continue to emphasize the importance of routine checkups, they can also adapt to the reality of irregular clinic attendance. The Zambia program reduced the number of recommended ANC visits and now emphasizes the importance of a few high-quality visits rather than a higher number of visits during which few services are provided. 


\section{Follow-up Care for HIV-positive Women}

In Africa, it is common for a mother to watch health workers treat her baby with antiretroviral drugs and then ask, "What can you do for me?" For all but a few HIV-infected mothers, ongoing ARV therapy remains unaffordable. However, health systems could meet many of their other health-related needs, including tuberculosis treatment and prophylaxis. Moreover, clinics and other health programs can be important sources of referral for the many other services that HIV-infected women require (financial support, school fees, nutrition) but that are beyond the ability of the health system to provide.

\section{Experience to date}

As PMCT programs learn more about the health and psychosocial needs of HIV-positive women, they increasingly recognize the importance of linking PMCT to effective follow-up care. Such efforts have focused on forging ties with existing care and support services. In Zambia, the national PMCT program links HIV-positive clients with WHO's Pro-TEST program for prevention of tuberculosis and other opportunistic infections associated with HIV, with the World Food Program for nutritional supplementation, and with community NGOs providing psychosocial and economic support and child care. The Kenya PMCT program refers clients to Women Fighting AIDS in Kenya and to Médecins sans Frontières. The Ndola PMCT program refers women to Mother Support Groups, and the Uganda PMCT program links with the National Community of Women Living with HIV/AIDS. In India, YRG Care provides drugs for prevention and treatment of opportunistic infections.

Despite these efforts, referral systems are struggling to become effective. For example, the Ndola Demonstration Project created a network that includes NGOs as well as government health institutions. So far, however, only referrals from government health centers to hospitals are taking place. Few clients referred from government facilities to NGOs are using the private services, perhaps because NGO fees are too high.

The success of such linkages is critical, because follow-up efforts for all women - regardless of HIV status - are weak. In the past, health services took responsibility for follow-up during and immediately after pregnancy. However, with widespread reductions in health services staff, too few workers are available to visit HIV-positive women at home or to provide follow-up counseling of HIV-negative women for risk reduction (see the discussion in section 3.c). Moreover, relatively few mothers attend the six-week postpartum visit recommended by most programs. After the postpartum visit, clinic staff [see the mother only when the baby needs to visit the clinic; women do not return for their own health needs unless they are experiencing a medical problem, and institutions do little proactive follow-up. Follow-up by community health workers (private practitioners, traditional healers, and others) could be an option in some areas, but many communities are already overburdened by having taken on services once considered the responsibility of the government. 


\section{Hgrizons}

Another key factor hampering follow-up efforts is the reluctance of many PMCT clients to disclose their HIV status outside the ANC clinic. Many women who choose VCT during antenatal care establish trusting relationships with staff and fellow patients, and are able to talk about their HIV status within the clinic walls. In general, however, women are still reluctant to disclose their HIV status in other settings, particularly in their neighborhood, and fear the stigma that may result from home visits. Such postpartum home visits were once common, especially after difficult deliveries, but young mothers today are not familiar with the practice. Alternative approaches such as using community-based child growth monitors or PLHA peer counselors to follow up mothers have yet to be tested.

Fear of stigmatization also leads most infected mothers to shun existing PLHA support groups. Moreover, currently such groups have little to offer the majority of pregnant women. Most are composed of healthy pregnant women, and PLHA groups typically focus on care and support for people with full-blown AIDS and in deteriorating health. In the Kenyan districts of Ndola and Homa Bay, HIV-positive women are reluctant to participate in post-test support groups. Elsewhere, women do join. In Dar es Salaam, it is reported that support groups originally formed in association with specific studies do not want to disband. Also, AIC in Uganda has successfully developed posttest clubs and support groups for couples in which one partner is HIV-positive.

\section{Practical strategies to improve follow-up care for HIV-positive women}

- Develop a system-level strategy for managing HIVAIDS in the same way as for other chronic diseases. Such a strategy would include disease prevention and life planning as well as defining roles for health facilities and community groups.

- Change clinic procedures. Provide incentives for follow-up, such as no-wait appointments and free food or health care services. Create HIV clinics in hospital outpatient departments to address medical needs such as opportunistic infections and to refer clients to other serviceswithin or outside the hospital - that provide psychosocial and material support and that address stigma. Introduce clinic-based peer counselors and support groups into PMCT programs.

- Refer women to other health services and to community groups for comprehensive HIV care, but ensure that these services are accessible, affordable, and acceptable to the client population. In Zimbabwe, large commercial farmers pay for community health workers to provide health services for the community. Such support could also be sought for additional staff at health facilities. In Thailand, as an incentive, trained community health workers receive free health care for themselves and their families.

\section{Supporting HIV-negative Women in Risk Avoidance}

Even where HIV prevalence is high, the majority of women test negative. Nonetheless, promoting HIV prevention at this juncture is critical because infection rates in the postpartum period are high in many countries. In southern Africa, 5 to 10 percent of HIV-negative women become infected in the year after they give birth. For those women who do test negative, counseling provides an 


\section{HIV and MCH Consultation Report}

important opportunity to frankly review potentially risky behaviors of the woman or her partner and to discuss strategies for reducing risk.

\section{Experience to date}

PMCT programs are where many women learn they are not infected with HIV. In fact, where MCH services have incorporated VCT, the numbers of women being tested in conjunction with antenatal care far exceeds the volume of clients served by other VCT programs. Nonetheless, hardly any $\mathrm{MCH}$ programs have strategies to address the prevention needs of HIV-negative women, and the few that do have been mostly unsuccessful. One such program in Zambia offered ongoing counseling and provided condoms to postpartum women. Despite these efforts, between 10 and 15 percent of the women who participated in the program were infected with HIV after one year. Rates were higher for women whose partners never accompanied them for counseling. Two women infected their babies through breastfeeding. One possible reason the program failed is that although women had sufficient information on HIV prevention, they were unable to communicate and negotiate safe sex — including condom use — with their partners.

The way services are currently structured offers little opportunity to counsel HIV-negative women on risk reduction. As noted earlier in this report, most ANC services are overloaded. Demand for VCT often exceeds the supply of trained counselors, and the focus is on counseling HIV-positive women about reducing the risk of transmission to their infants and caring for themselves. This leaves little or no time for ongoing counseling and support for risk avoidance. Also, follow-up occurs only when the client or provider perceives a problem. Thus, no mechanism and little encouragement exist for HIV-negative women to return to the ANC clinic for further counseling.

\section{Practical strategies to support risk avoidance}

- Promote couple counseling. One study found that in couples where the man tests positive but the woman tests negative, the likelihood that the woman becomes infected within a few years is very high. If both partners test negative, men have a very strong incentive to remain free of HIV. Thus, when both members of a couple test negative or one tests negative and the HIV status of the other partner is unknown, programs should recommend that women periodically assess the HIV status of their partner (Voluntary HIV-1 Counseling and Testing Efficacy Study Group 2000).

- Use personal testimony to change behavior. In Uganda, the use of personal testament is a powerful strategy to support PLHA, reduce stigma, and ensure that women remain infectionfree. In Zambia, the PMCT program provides transport to mothers willing to talk to pregnant women about their success in negotiating condom use, breastfeeding exclusively, or using infant formula. These talks seem effective in communicating important messages about risk avoidance.

- Build counseling expertise in community institutions outside the clinic setting. This approach can reduce demand on staff time and take advantage of the fact that people generally fear loss of confidentiality less from workers in community-based organizations than from public sector 


\section{Hgrizons}

health workers. Key to such an approach is promoting a positive relationship between clinic staff and community health workers. This involves first changing ingrained attitudes that pregnancy care is the sole responsibility of professional health workers. Second, clinic staff must share their knowledge and thus build credibility for lay workers, whom the community may not initially see as credible sources of information and services. In India, NGOs provide HIV counseling in urban ANC clinics, and midwives go door-to-door in rural areas. In Kemba, Zambia, traditional birth attendants selected by the community offer supportive counseling. The District Health Management Team in Ndola, Zambia, has incorporated a variety of community health workers into their PMCT programs. However, the apparent unwillingness of many community members to discuss HIV with their neighbors has so far limited the effectiveness of these community workers.

- Offer ongoing supportive counseling and condoms. PMCT counselors should be trained and rewarded to encourage HIV-negative women to return for help in communicating with their partners and introducing condoms into their sexual relationships, if appropriate, to reduce their risk of HIV infection. PMCT programs could support women in doing this as well as attract men by making condoms freely available as part of the service.

\section{Voluntary Counseling and Testing Services}

High-quality, confidential counseling - either for individuals or couples - combined with timely, accurate HIV testing offers a number of benefits, including improved health status through good nutritional advice and earlier prevention of or care for HIV-related illness, emotional support, better ability to cope with HIV-related anxiety, awareness of safer options for giving birth and infant feeding, and motivation to initiate or maintain safer sexual and drug-related behaviors. VCT has traditionally taken place in clinics set up for treatment of sexually transmitted infections, hospital outpatient departments and wards, special VCT centers, or clinics for special high-risk populations, such as sex professionals. In the MCH setting, VCT has the potential to reach large numbers of women who may already be infected with HIV or be at high risk of becoming infected.

\section{Experience to date}

The response to VCT services in the MCH setting has so far been overwhelming. In one year, three different PMCT programs in Kenya and Zambia provided VCT to between 1,000 and 5,000 women attending ANC clinics. Swamped with requests from women for VCT, counselors often work through lunch and into the evening. Nonetheless, a major concern is that other clinic staff consider HIV-related concerns something that the counselor alone addresses. Ideally, all ANC providers should include PMCT in discussions with a mother about the wellbeing of her baby. However, time constraints during provider-client interactions continue to be a major deterrent to such an integrated approach.

To accommodate VCT, health facilities have been refreshingly open to modifying procedures, patient flow, and the roles and responsibilities of health workers. For example, in PMCT projects in Kenya and Zambia, women first receive a health talk that includes information about VCT. After 


\section{HIV and MCH Consultation Report}

weight and blood pressure are taken, the women then receive group counseling and/or individual pretest counseling. The blood sample for the HIV test is also used for syphilis and hemoglobin testing. After post-test counseling, staff enter the test results on the client's ANC card exactly like any other test. In Uganda, officials of AIC and the Ministry of Health have developed a model to ensure that every health worker in the clinic can assess a client's need for VCT and refer the client appropriately. As a result, clients who come in primarily for other services such as family planning or tuberculosis care frequently augment their visit with HIV counseling and testing.

Even with very high levels of demand for VCT services, a large portion of HIV-positive clients do not receive counseling and testing. For example, in the Kenyan districts of Karatina and Homa Bay, VCT services identify only 60 and 41 percent, respectively, of HIV-positive women.

Moreover, officials are concerned that interest in VCT may decline after an initial enthusiastic response to mass information campaigns. Because providing VCT in the $\mathrm{MCH}$ setting is so new, experience in reaching those not currently served is limited. A related effort that may serve as a model is the experience of programs that promote VCT among youth and include strategies such as making VCT services more youth friendly, using peer counselors, and providing information about income-generating activities and social support.

One possible reason that VCT coverage is less than desired is the current "opt-in" testing policy, under which women must make a specific request to be tested. An alternative is to offer HIV testing as part of the routine battery of ANC tests and allow women to "opt out" if so desired. Such a policy currently exists in India and in a number of private hospitals in Nairobi. One potential pitfall of an opt-out policy is that women not wanting the test may be less likely to seek antenatal care, as they may find it difficult to opt out of a standard procedure. Support for making HIV testing of pregnant mothers routine - and even mandatory - also comes from those who believe that the primary aim of PMCT should be to safeguard the baby. In their view, the right of the child to protection outweighs the right of the mother to choose whether or not to know her HIV status. Since there is little experience with the opt-out strategy in Africa, many observers feel that further research is needed to compare the acceptability and uptake in ANC of the opt-out versus the opt-in strategy.

The high demand for VCT in the MCH setting also raises the question of whether public health services in Africa can afford the cost of routine HIV testing on a mass scale. Indeed, some workshop participants thought that countries should first use existing resources to increase the availability of high-quality, conventional antenatal care before adding an HIV testing component. These participants argued that good antenatal care alone could go a long way in improving child outcomes and might give better value for the money. Another concern is over the quality of counseling. As VCT becomes a routine element of antenatal care, counselors may have less time to provide a quality, client-centered service. Moreover, the potential for counselor burnout is high.

\section{Practical strategies to improve VCT}

- Expand health education outside the clinic. Mobilizing the community to provide information can create better-informed clients and save time at busy clinics otherwise spent giving basic 


\section{Hgrizons}

information and clarification. The community approach can also help to maintain demand for VCT, reach more women, and enable men and other family and friends to support a woman as she makes and carries out decisions about HIV and pregnancy. In addition, community programs could encourage men who undergo testing in general VCT clinics to refer their pregnant wives or partners to VCT services located at ANC sites. Such programs could also refer women who attend general VCT and HIV care services, as appropriate, to available PMCT services.

- Shift the counseling emphasis from pretest counseling to post-test support. Doing so can reduce waiting time for pretest counseling and lower the number of women who forego testing because of long waits. Another way to reduce the level of information needed during pretest counseling is to revise ANC procedures so that workers give PMCT information to clients at every point of contact. In addition, pretest counseling should focus on risk reduction rather than risk assessment. The bulk of psychosocial counseling should take place after the test, when the urgency to address emotional needs is highest.

- Diversify the sources of post-test support and ongoing counseling for mothers to supplement the limited time that women spend with the counselor during post-test counseling. Post-test clubs have been successful for clients of general VCT services, and should be tried with VCT clients from ANC settings. Another approach is to use peer counselors to help new mothers come to terms with their HIV status and to adopt practices that support PMCT, such as appropriate infant feeding choices (see section 5 below). PMCT programs should also increase efforts to refer clients to existing counseling and support organizations, and to emphasize the importance of return appointments.

- Assign dedicated PMCT counselors to antenatal clinics. Most PMCT program managers have successfully deployed dedicated counselors and feel that, because of the level of concentration and continuity required for VCT, this arrangement is the most adequate. To reduce burnout and to dispel the impression among other providers that HIV-related care is the exclusive responsibility of the dedicated counselor, programs can rotate HIV counseling responsibilities.

\section{Counseling on Infant Feeding}

Stopping the transmission of HIV through breast milk is one of the greatest challenges facing PMCT programs. Up to 20 percent of HIV transmission from mother to infant occurs during breastfeeding. Along with the application of other PMCT strategies, current standard guidelines for preventing breast milk transmission of HIV include:

- Providing HIV-positive women an opportunity to select an appropriate infant feeding choice from the options exclusive breastfeeding, shortened duration of breastfeeding, or replacement feeding with formula or locally available milk.

- For HIV-negative women, promoting exclusive breastfeeding and preventing new HIV infections.

Knowledge about the risks of transmission associated with various feeding choices is rapidly evolving, so experts are continually updating recommendations and guidelines. Furthermore, the decision about how to feed an infant is rarely the mother's alone but is strongly influenced by her partner and her family. Many women live in environments that make the preparation of safe 


\section{HIV and MCH Consultation Report}

replacement formula extremely difficult, if not impossible. Mixing breast milk with other foods, the most common infant feeding pattern, is also the pattern that produces the highest risk of HIV transmission.

Helping women make informed choices about feeding also has an impact on the acceptability of other components of the PMCT package. Many women who decline to use infant formula because they are concerned about revealing their HIV status also reason that if they cannot use the milk then they will not bother with the antiretroviral drugs. The determination of providers and women to adhere to the ARV regimen can be undermined if they feel that any good stemming from the use of ARVs will be undone by women refusing to use replacement feeding.

\section{Experience to date}

The early experience from introducing an HIV-related infant feeding component to $\mathrm{MCH}$ care has been promising. Most health workers in PMCT programs in Kenya and Zambia who received training in infant feeding counseling ${ }^{1}$ feel much more confident about their ability to provide clients with good information about the relationship between HIV and appropriate infant feeding practices. Evidence from Kenya shows that the introduction of infant feeding counseling increases the number of clients who receive counseling on maternal nutrition and infant feeding. Such counseling was rare before the PMCT training.

To support these programmatic efforts, a number of countries in sub-Saharan Africa have adapted WHO/UNICEF guidelines to develop policies on HIV and infant feeding. For example, national guidelines in Uganda propose that health workers first equip women with breastfeeding skills, then provide options if a woman chooses not to breastfeed. In countries such as Zambia, however, policies have remained in draft form for years, and often change as new findings on infant feeding emerge, thus confusing health workers looking for clear guidance.

Despite the increase in counseling on infant feeding, many health workers still struggle to provide good information to mothers. For almost all frontline health workers, the topic is new and complex. In Kenya, staff cuts in the public sector have reduced the number of nutritionists and lactation specialists, leaving few sources of on-the-job help for health workers. A particularly critical area for improvement is coaching mothers how to respond to family members and neighbors who question their use of formula. Fearing stigma, most women want to keep their HIV status confidential, and do not want to reveal the true reason they formula-feed their baby. For example, one couple in Kenya told neighbors, "Mom doesn't have enough milk and is saving it for nighttime feeds." In Thailand, many HIV-positive mothers say that the baby is not growing well and that the formula is supplemental. The Thai data on the national expansion of PMCT show a 6 percent transmission rate in the randomized control trial of AZT, 8 percent in the pilot area for the national program, and 12 percent when the pilot was scaled up to other regions. The difference could be due to the women's difficulty in formula feeding. Furthermore, while providers and women know that breastfeeding can transmit HIV and are aware of feeding alternatives, they do not always

\footnotetext{
${ }^{1}$ In both countries, PMCT programs use an adapted WHO curriculum for their training.
} 


\section{Hgrizons}

understand that exclusive breastfeeding is better prevention strategy than mixing breastfeeding with other foods. Such misconceptions may hamper the ability of health workers to provide balanced information to women on feeding choices.

Nonetheless, allowing mothers to make informed decisions about infant feeding practices is an area where the training has apparently brought about some improvement. To many health workers, who are accustomed to making decisions for their patients, handing over decision making to mothers threatens their authority. However, the experience from PMCT programs in Kenya and Zambia suggests that health workers are not unduly influencing the infant feeding choices of women. For example, only half of the women in Zambia for whom infant formula is recommended are accepting the formula - even though it is free. Women cite various social, convenience-related, and cost factors when weighing their decision. In Kenya, some women refuse exclusive breastfeeding because their work schedules or other factors make it difficult to sustain.

The success in convincing HIV-positive mothers to accept replacement feeding has been limited, and is related to a variety of factors. Practical reasons, such as the difficulty of fixing formula at night, cause many women who initially choose not to breastfeed to "regress" to breastfeeding. In both rural Zambia and urban Kenya, relatively high levels of uptake of formula feeding have been linked to greater levels of male involvement. For example, at Kenyatta National Hospital in Nairobi, husbands and male partners often appear for HIV education and learn enough to decide to support formula feeding. Similarly, a small study in Zimbabwe found that when mothers and fathers collaborate, formula feeding is more successful. Also, where there is a history of promoting formula feeding for HIV-positive mothers, such as in Nairobi, the stigma is less and more mothers have been willing to formula-feed.

There is also some evidence that social class affects acceptance of and effective practice of replacement feeding. For example, uptake of formula feeding has been higher among the more affluent, independent career women attending Zambia's University Teaching Hospital than among less-educated, poorer women. Poorer women may also be less able to resist the social pressure to breastfeed. In some low-income, rural townships, women choose not to breastfeed initially but then start, probably due to the influence of neighbors and friends. Other evidence shows that some poor mothers may divert formula milk to feed other children, a practice that is difficult to monitor.

Another area needing further study is weaning, which if done abruptly can be traumatic for the baby, according to a recent literature review (Piwoz 2001). Currently, programs are promoting a number of different weaning strategies. The Zambia Exclusive Breastfeeding Study recommends that mothers start to express milk at two months and feed it to babies with a cup and spoon. A program in Monze, Zambia, recommends starting cup feeding of expressed breast milk at five months, stopping breast milk and using formula for a few weeks at six months, and then introducing other foods. In India, YRG Care provides HIV-positive mothers with the drug Bromocryptine to inhibit milk production, provides cups, and counsels women that breastfeeding will diminish the impact of taking ARV drugs for PMCT. However, there are concerns about the safety and cost of Bromocryptine. The Zambia program considered but ultimately rejected including the drug as part of the minimum package of PMCT interventions. 


\section{Practical strategies to improve infant feeding counseling}

- Provide interim guidance on feeding practices. Such guidance is important, even though experts are still debating the best way for HIV-positive mothers to feed their infants. At the same time, further research is needed to determine whether providers and clients fully understand the preventive value of exclusive breastfeeding.

- Expand and improve training to build skills in infant feeding counseling. Preservice and inservice training for doctors, nurses, and community health workers should include instruction on infant feeding counseling. For in-service training, improvements could include adding a third week to the minimum package of training for MCH staff, or adding refresher training or separate training for infant feeding counselors. All training should incorporate innovative health education techniques such as drama.

- Document challenging situations and how women handle them. Counselors can share these experiences with other women to suggest ways women can explain and manage their feeding choice. Counselor training should include role-playing that gives providers practice in handling difficult questions and situations.

- Include planning for practicing formula feeding as part of counseling. Women should practice having water ready in a flask, premeasuring formula in a cup, and other tasks they will need to perform.

- Promote proper infant feeding practices through Integrated Management of Childhood Illness programs. One study in Zambia found that among providers trained in IMCI guidelines, 80 percent discussed infant feeding as part of the assessment of the child. Programs could adapt IMCI guidelines to ensure that HIV-related concerns are taken into account.

- Encourage the transition from exclusive breastfeeding to weaning-by-cup-using expressed breast milk. The two programs in Zimbabwe described above use this method.

- Develop weaning foods based on locally used ingredients. The MTCT Working Group in Zambia approached the Zambian National Research Council to develop a weaning formula based on local foods (for example, corn, oil, and sugar).

- Involve men in infant feeding counseling. As noted above, this approach has yielded positive results in Kenya, Zambia, and Zimbabwe.

\section{Antiretrovirals to Reduce Mother-to-Child Transmission}

Giving antiretroviral drugs to pregnant, HIV-infected women can decrease the mother-to-infant transmission rate significantly by reducing transmission during pregnancy and childbirth. In East and Southern Africa, two common ARV regimens coexist. The first is a short course of zidovudine (AZT). This entails $300 \mathrm{mg}$ of AZT twice a day starting at a gestational age of 36 weeks, and 300 mg every three hours during labor. No drugs are taken by the mother or infant postpartum. This 


\section{Hgrizons}

regimen was shown to reduce transmission during pregnancy and childbirth by 50 percent (Shaffer et al. 1999). ${ }^{2}$ The second regimen uses the drug nevirapine and is based on the results of the HIVNET 012 study. The study showed that a single $200 \mathrm{mg}$ dose of nevirapine to the mother at the onset of labor and a single dose of nevirapine ( $2 \mathrm{mg}$ per $\mathrm{kg}$ of birth weight) to the infant within 72 hours of birth reduced transmission of HIV during pregnancy and childbirth by 44 percent (Guay et al. 1999).

\section{Experience to date}

PMCT programs in Sub-Saharan Africa use a mix of approaches for providing ARVs. Some of the early programs (for example, the MTCT-WG in Zambia and the PMCT Project in Kenya) use the AZT short course as the first-line regimen and provide nevirapine for women who will not be able to appropriately use AZT. Uganda also started with AZT and will add nevirapine as new PMCT sites begin to offer services. In Kenya, most sites that introduced services in 2001 (for example, Busia, Kakamega, and Kisumu) adopted nevirapine from the outset. PMCT programs have trained their staff and organized their services to be flexible and responsive to the continuous flow of new information on the use of ARVs for preventing mother-to-child transmission and thus are able to maximize feasibility and safety when selecting drug regimens for their programs.

Most plans for scaling up PMCT services propose using nevirapine, primarily because of its low cost and ease of administration compared to AZT. Nonetheless, many programs are not ready to fully commit to using nevirapine because of lingering concerns about the drug's safety and, until recently, erratic availability and the absence of government approvals. Moreover, some uncertainty still surrounds the effectiveness of nevirapine in routine use. ${ }^{3}$

However, nevirapine remains an important program option, especially for women who cannot adhere to the minimum two-week dose plus labor doses of AZT. This group includes women who are first seen for antenatal care after 36 weeks of gestation or are seen not at all until delivery. It also includes women who will be unable to take their labor doses because they give birth unassisted or with the assistance of traditional attendants or family members to whom they do not want to reveal their HIV status. Furthermore, many women deliver before 38 weeks of gestation, and thus do not receive the minimum two-week dose of AZT. ${ }^{4}$ In addition, poor nutrition and low hemoglobin precludes (or should preclude) the use of AZT for some women. AZT is associated with a drop in hemoglobin levels, and PMCT guidelines recommend that, to avoid severe anemia, women with hemoglobin levels of less than 8 grams not receive AZT. In many settings, women are

\footnotetext{
${ }^{2}$ Often referred to as the "Thai regimen" because its efficacy was documented in a breakthrough study in Thailand. A variation of this regimen that included a postpartum dose was tested in Abidjan, Cote d'Ivoire. Women were prescribed $300 \mathrm{mg}$ of zidovudine twice a day from 36 weeks of gestation, $600 \mathrm{mg}$ at onset of labor, and 300mg twice a day for one week following delivery. This regimen resulted in a 38 percent reduction of transmission during pregnancy and childbirth (Wiktor et al. 1999).

${ }^{3}$ By pooling data from Horizons-sponsored studies at different PMCT sites, observations will be available in sufficient numbers to measure real-world effectiveness of the use of nevirapine.

${ }^{4}$ There may be an overall trend toward early delivery linked either to the poor nutritional status of women or to a predisposition among HIV-infected women to give birth prematurely.
} 


\section{HIV and MCH Consultation Report}

not having their hemoglobin levels checked before receiving AZT because of insufficient testing supplies or fees they cannot afford.

In general, PMCT programs still know little about what happens when women take ARVs, whether they are actually using them, and how much they take. Clearly, however, stigma toward HIV-infected mothers, as well as misconceptions about ARVs, are important obstacles to the uptake of ARVs and adherence to drug regimens. Stigma manifests itself in a number of ways. First, ignorance and misconception about antiretrovirals is rampant; common rumors are that ARVs put women to sleep during labor (and leave them exposed to assault) and that taking the drugs will deform or kill a baby. In Zambia, such rumors have led to a number of women refusing to take the drugs after they had brought them home from the clinic. In one community in Kenya, three women returned their drugs because of resistance from their husbands. Second, stigma makes women reluctant to share their HIV status and information about PMCT with their spouses and even with other health workers. Many such women succeed in concealing ARV use at home but are unable to hide the drugs from health workers and thus forego the critical labor dose rather than face the negative attitudes of health workers in the labor and delivery suite. One workshop participant told of an HIV-positive woman in labor who wanted to take her labor dose of AZT and asked for water. The midwife asked her why she wanted water and the woman explained. The midwife immediately refused to provide any further care for the woman, calling for a student nurse to take her place. Other workshop participants related hearing similar critical comments from midwives or witnessing sudden negative changes in attitudes toward a patient once their HIV status was revealed.

Recognizing the impact of stigma and other barriers, many PMCT programs work to help women adhere to ARV treatment regimens. Kenyatta National Hospital provides women with a timetable and asks them to mark each time they take a tablet, to come back with the drugs to check adherence, and to return unused tablets to give to other women. In Zambia, women receive weekly supplies. Where home birth is common, traditional birth attendants have helped meet the challenge of ensuring that women still get their labor dose of ARVs. In Keemba, a rural area in Zambia where more than 90 percent of women deliver at home, the PMCT program provides women with a weekly supply of AZT plus an additional dose for labor. During counseling with HIV-positive women, the nurses reinforce the necessity of taking a labor dose of $600 \mathrm{mg}$. Importantly, the nurses work with TBAs to inform them about PMCT and about the need for some women to take these drugs during labor. Births attended by TBAs are registered at health centers, usually the following day, at which time the nurse inquires about and documents whether the mother successfully received her labor dose of AZT. To date, the program has had four cases of women who delivered with a TBA and successfully took their labor dose. Still, more training of TBAs is needed in areas where home delivery is the norm.

One of the most difficult tasks PMCT programs face is how to address the need that infected mothers have for ongoing ARV treatment. While a number of promising initiatives to expand ARV access exist, the availability of drugs and related diagnostics will be very limited for the immediate future. The lack of ARV treatment options for mothers undercuts support for and effectiveness of PMCT programs. A common criticism, both from health officials and from the community, is that PMCT programs save children's lives only to later create vulnerable orphans. Program managers 


\section{Hgrizons}

have formulated a number of responses to counter these criticisms. First, they point out that even if a mother dies from AIDS, it is easier-both emotionally and financially - for families and communities to care for a healthy child than a child sick from HIV/AIDS. Second, many HIVpositive mothers are healthy and can expect to live a number of years. An uninfected child is a benefit to these mothers.

At the same time, community concern about the welfare of the children of HIV-positive mothers can be a powerful tool to promote broader access to ARV drugs for the mothers who participate in PMCT programs. Some of the reasons that these women should be a priority treatment group are that:

- They have taken the positive step of requesting an HIV test to improve the health of their family.

- They already have experience with the ARVs used to prevent mother-to-child transmission.

- Improving the health of HIV-positive mothers will benefit both mothers and their children.

\section{Practical strategies for promoting ARV use for PMCT}

- Sensitize the community about preventing mother-to-child transmission. Ultimately, communities should view PMCT as a routine part of ANC, where a mother, supported by her spouse and family, takes standard steps (including testing for HIV, taking ARVs if appropriate, and making an informed decision about infant feeding) to have a healthy, HIV-free baby.

- Stress the benefits of PMCT for mothers themselves. PMCT programs can help mothers either through health services offered at the same facility as the PMCT program, through referrals to other sites, or via links with community groups. These services include screening and treatment for tuberculosis; treatment and prophylaxis for opportunistic infections; nutritional support; psychological, economic, and social support; and child care.

- Train TBAs to oversee use of ARVs and use the system of birth registration to monitor use of ARVs outside health facilities. Such training should focus on the risks of HIV transmission during labor and delivery, safe labor and delivery, avoiding practices such as rupture of membranes that can increase the probability of HIV transmission from mother to baby during birth, support for the mother to complete her course of ARVs, helping mothers to initiate their infant feeding choice, and the importance of seeking postnatal follow-up for the mother and baby.

- Change procedures to encourage greater adherence to ARV regimens. Such changes could include training labor and delivery staff (including midwives in neighboring private facilities) in PMCT; strengthening communication between the ANC and the delivery point to ensure that women get their ARV dose during labor; encouraging early booking for ANC and initiating AZT at 34 weeks to increase the number of women who receive at least two weeks of AZT; considering administering ARVs to the babies of women who receive less than two weeks of AZT; testing for hemoglobin levels, providing nutritional support, and exploring using nevirapine with women with hemoglobin levels under 8 grams; using calendar or other followup methods to monitor adherence to ARVs; and offering couple counseling on ARVs. 


\section{HIV and MCH Consultation Report}

\section{Involving Male Partners}

Preventing HIV infection in mothers and fathers is a key facet of PMCT. Thus, male involvement is important not only as a means to good pregnancy care, but also as a way to improve reproductive and sexual health. For many couples, pregnancy is a time when communication may become easier as partners discuss their hopes and concerns for their future child. Many women also feel that men, as heads of household, should be involved in decisions about the pregnancy. Thus, the antenatal care setting can provide a window of opportunity to involve men more deeply in the care of their partner and child. Such involvement can mean many things, depending on the couple and the community. Some men may choose to come to the clinic with their wives or partners, get involved in counseling, and get tested for HIV. Others may not visit a clinic, but support their partners in coping with HIV and in PMCT in other ways. Some men pay for their partner's health care, while others transport their partner to the clinic.

\section{Experience to date}

$\mathrm{MCH}$ programs have tried a number of strategies to involve men in HIV-related care. A program in Zimbabwe uses farm health workers to help the community promote couple counseling at the local ANC clinic. One of the slogans developed by the community is "Mira Newako," which means "stand with your own spouse with pride." During the formative stage of the project, the community helped to design, discuss, and vet the promotional materials. This process boosted the number of couples visiting the ANC clinic from 2 to 39 per week, even before the interventions officially began. The PMCT project in Keemba, Zambia, successfully persuaded men to get involved in PMCT by working with male community leaders and talking to men directly. More than half of the male partners of women tested for HIV at the ANC clinic have also received testing. The AIDS Information Center in Uganda operates a campaign to promote couple counseling by providing free VCT to couples on occasions such as Valentine's Day. Currently, 30 percent of clients seeking VCT at AIDS Information Center sites come as couples. In Kenyatta National Hospital, education and counseling address the impact of pregnancy on men. Talks about formerly taboo subjects such as sex during pregnancy have been well received by men.

Although many ANC programs are trying to adapt services to involve male partners, large gaps still exist. Current ANC services are, for the most part, not designed to welcome men. Frequently, staff and women clients at the ANC clinic consider men as intruders, and a lack of privacy for female clients reinforces the attitude that such clinics are for women only. Clinics are usually closed at the times when working men can most easily attend - during evening hours and on weekends. The lack of "male-friendly" services confirms the perceptions among many men that male involvement benefits women and not men. Comments by men in one project in Zimbabwe typify this viewpoint: "Is it all an issue of wasting our time for the sake of the woman and her baby?" "Is this another show of power for the women to drag us men to the clinic?" "How come all the health workers counseling couples are women?"

Such attitudes are closely related to deeply ingrained community norms that limit men's involvement in pregnancy care. For example, community discussions in the male involvement 


\section{Hgrizons}

project in Zimbabwe revealed that men are usually the source of information for new programs and technologies in their community. They have the social and psychological power to decide what is acceptable. And yet men are not well informed about health issues. Men are also not used to seeking services with their spouses; in fact, men usually seek treatment for sexually transmitted infections on their own. Some communities consider as weak or "bewitched" the man who publicly supports his wife by accompanying her to the clinic.

The realities of male-female relationships complicate programs to involve men. Men often have multiple sexual partners, and may not want to make a "public appearance" at the MCH clinic with one of those partners. Many women have no male partner to accompany them, either because the partner has another family and hence is not available or willing to join her; because the partner may not be able to get time off from work; because the partner has died; or because a partner may not wish to be seen and associated with a teen mother. Overemphasizing the need to "stand with your own partner with pride" may stigmatize such women. For other women, some kinds of male involvement may actually be harmful. For example, some women feel they can take more effective action to prevent mother-to-child transmission if their partner does not know about her HIV test. Furthermore, because male involvement is so couple-specific, measuring the ideal degree of involvement is very difficult.

\section{Practical strategies to increase male involvement}

- Change community norms to promote male involvement. To address community-wide beliefs that limit male involvement, programs in Zimbabwe have targeted people other than male partners, including grandparents, in-laws, and young people. Using information campaigns and mobilization activities, the program hopes to make male involvement in matters of pregnancy a sustainable community norm.

- Give information on PMCT to men directly-not through women. Where such an approach was tried in Keemba, Zambia, men were often the initiators of VCT. This behavior is in contrast to other areas, where women are asked to bring in their partners after they receive VCT at an ANC clinic. Indeed, the village chief in Keemba was among the first to come with several of his wives to receive VCT. Influential male community leaders have had a similar influence on men on commercial farms in Zimbabwe.

- Consider the interests of men when planning couple counseling. Although the number of men attending couple counseling is not high yet, PMCT services need to plan for an influx of men and adapt counseling accordingly. One approach is to include topics of relevance to men, such as sex during pregnancy. Programs should offer afternoon and weekend hours for couples and seek the support of employers to give men time off for clinic visits.

- Empower women to communicate with their partners. Many women, for whatever reason, cannot bring their partner to a counseling session, but still need help disclosing their HIV status to and talking with their partner about PMCT. One approach is to use group discussions among women to allow them to share ideas about how to discuss sensitive issues with men. Another approach is to provide "couple-oriented" counseling that includes role-plays on how to raise the issue of HIV with a woman's partner. 


\section{Conclusion}

Horizons studies - many of them yet to be completed - are already generating a wealth of information about the feasibility and effectiveness of providing HIV-related services in the $\mathrm{MCH}$ setting. The following key themes have emerged from the experience to date:

- Success in integrating elements of HIV-related care has been mixed. Although programs appear to be adequately training health workers, motivating and supervising staff who provide HIV-related services remains a challenge. The introduction of voluntary counseling and testing services into the ANC setting has been enormously popular among clients, but programs now face the problem of maintaining this demand and coping with success. Efforts to promote appropriate infant feeding practices for HIV-positive mothers have been cautiously successful. Progress has been especially slow in adequately addressing the follow-up needs of motherswhether they are infected or not with HIV. Little is known yet about the effectiveness of efforts to provide ARV treatment to prevent MTCT, except that stigma and misconceptions are formidable barriers. Finally, programs increasingly recognize the important role of male partners, but are still struggling with how to effectively involve men.

- Generalized shortcomings of health systems continue to hobble efforts to integrate HIV-related care into MCH settings. Integration has not been easy in an environment where ongoing problems such as shortages of staff and medical supplies, inadequate supervision, and lack of good monitoring and evaluation afflict existing MCH services. Many of these problems are related to the funding constraints facing the public sector almost everywhere in the developing world.

- Stigma toward HIV-positive women remains a major factor limiting the effectiveness of HIV services. Recognizing this, many programs use strategies to counteract the harmful effects of stigma. Within the clinic walls, programs have had some success in improving staff attitudes and in shielding women through improved confidentiality. Simply having daily contact with large numbers of HIV-positive women has helped to improve attitudes. Yet, outside the clinic, where programs have much less influence, stigma - or fear of it — continues to hamper attempts to involve families and communities in HIV-related care.

- The disparate nature of HIV-related services complicates integration efforts. HIV-related care covers a relatively broad range of topics requiring a diverse set of knowledge and skills. Tying together such care in a comprehensive and cost-effective way has been challenging, particularly when separate funding streams support the different components.

The practical strategies elaborated in response to this experience can be summarized under four key actions:

- Make HIV-related care the norm in MCH care. True success in integration will come when health workers and their clients view HIV-related services as a routine part of the $\mathrm{MCH}$ care 


\section{Hgrizons}

experience. Programs can act broadly to bring about such change, including appropriately training health workers (both preservice and in-service), adjusting policies and clinic procedures, and influencing public attitudes. Such efforts will have the added benefit of reducing the stigma attached to HIV-positive women.

- Strengthen ties between the MCH clinic and outside sources of care. HIV-related services can extend their reach and effectiveness by better links with public sector entities, NGOs, the private commercial sector, lay workers, TBAs, families, husbands, and community leaders. Such efforts will also help to address the underlying causes of stigma by helping to change community norms.

- Promote incremental, low-cost changes. Although integration of HIV-related care may require a large initial investment in training, supervision, and other elements, many of the practical strategies proposed during the workshop-for example, modifying the frequency of antenatal visits, redefining job descriptions, or rotating counseling responsibilities-require relatively little outlay. Program officials who want to make improvements, yet face budget constraints, can consider such gradual changes in operations.

- Work long-term to create a policy environment favorable to integration. $\mathrm{MCH}$ programs alone cannot address the many structural factors - including poor motivation and staff and materials shortages - that limit access to HIV-related care. However, advocates for PMCT, VCT, and other services can join with others to improve overall policies and increase allocation of resources for health programs, and to promote policies such as free or low-cost care that increase access. Advocates for HIV-related care can also push for policies to ensure that women and their families affected by HIV/AIDS receive better support for their nonhealth needs, including education, child care, and nutritional and economic support.

To make these strategies effective, better information is needed. Improved monitoring and supervision will allow programs to fine-tune interventions. Evaluation showing the costs and effectiveness of the various interventions will provide invaluable guidance to program managers and policymakers, and a powerful argument for increased funding of cost-effective interventions. Such information can provide the basis for scaling up the interventions to ensure that, eventually, women everywhere will have access to quality HIV-related care. 


\title{
Appendix A
}

\section{Agenda}

\author{
Integrating HIV Prevention and Care into MCH Settings: \\ Workshop to Synthesize Lessons Learned from Horizons Studies \\ July 23-26, 2001 \\ Masai Mara, Kenya
}

\section{Sunday, July 22}

Late morning Arrive Fig Tree Camp, Masai Mara

Lunch and relaxation

5:00-6:00 Introduction of participants and objectives

Naomi Rutenberg, Horizons

6:00-7:00 Reception

Monday, July 23

9:00-9:30 Overview of HIV prevention and care services in MCH setting Sam Kalibala, Horizons

Introduction to Integrated HIV Prevention and Care and MCH Programs-Program

Overviews: What are the program objectives and major activities? What are major milestones and accomplishments? How is impact being measured?

9:30-9:40 PMCT Kenya

9:40-9:50 MTCT-WG Zambia

9:50-10:00 Ndola Demonstration Project

10:00-10:10 HIV and Partner Violence in Tanzania

10:10-10:20 Male involvement in Zimbabwe

10:20-10:30 Integration of VCT in Uganda

10:30-10:40 Youth and VCT in Uganda 


\section{Hgrizons}

10:40-10:50 Experience from Thailand

10:50-11:00 Experience from India

11:00-11:20 Coffee Break

11:20-12:50 Question and Answers and Discussion of Program Objectives, Successes, and Challenges

Moderator: Charles Mwai, Horizons

12:50-2:00 Lunch

Discussion of Key Themes for HIV Prevention and Care in the MCH Setting: For each theme, the task was to (1) identify what has and has not worked in terms of the feasibility of providing the service, the acceptability of the intervention, and the effects of the intervention (e.g., Did the service contribute to women's making informed choices about HIV prevention and care, making those choices safely, and addressing stigma?) and (2) develop program recommendations, paying particular attention to the need to not only replicate but also scale up the service.

2:00-3:45 Capacity Building: Provider Training, Motivation, and Protection Presenter: Jennifer Oyieke, Moderator: Anna Banda

3:45-4:00 Coffee Break

4:00-6:00 The M in MTCT: Antenatal Care, Providing Follow-up Care to HIV Positive Women, Supporting HIV-Negative Women in Risk Reduction, and Effective Referral

Tuesday, July 24

Presenter: Omondi Ogutu, Moderator: Paul Waibale

6:00-8:00 Game Drive Opportunity

9:00-11:00 Organization of Counseling and Testing

Presenter: Esther Tumuhairwe, Moderator: Jessie Mbwambo

11:00-11:15 Coffee Break

11:15-1:00 Antiretrovirals to Reduce Vertical Transmission

Presenter: Margaret Siwale, Moderator: Ruth Nduati

1:00-2:00 Lunch 
$2: 00-3: 30$

$3: 30-4: 00$

$4: 00-5: 30$
Infant Feeding Issues

- Counseling - what is possible to discuss; how to facilitate informed choice

- Implementation of infant feeding choice

Presenter: Ruth Nduati, Moderator: Sam Kalibala

Coffee Break

Infant Feeding Issues (continued)

\section{Wednesday, July 25}

6:00-8:00 Game Drive Opportunity

9:00-11:00 Involving Partners and the Community, Addressing Stigma

Presenter: Ravai Marindo

Moderator: Esther Sakala

11:00-11:15 Coffee Break

11:15-1:00 Supervision and Quality Assurance

Presenter: Ernest Muyunda

Moderator: Chipepo Kankasa

1:00-2:00 Lunch

2:00-3:00 Supervision and Quality Assurance (continued)

3:00-3:30 Coffee Break

3:30-5:00 Monitoring, Evaluation, and Research

- Lessons learned about data collection

- Setting operations research priorities for Horizons

- Dissemination and utilization of research findings

Presenter: Naomi Rutenberg

Moderator: Ravai Marindo

5:00-5:30 Wrap-up

Sam Kalibala, Horizons

Thursday, July 26

9:00

Departure for Nairobi

Afternoon

Free (bus available to town center) 


\section{Hgrizons}

Appendix B

\section{List of Participants}

Ellen Irungu

Karatina District Hospital

P. O. Box 133

Karatina, Kenya

Tel.: 254-0171-71471, 71154

Fax: 254-0171-71471

Christine Nyakiamo

Homa Bay District Hospital

P. O. Box 52

Homa Bay, Kenya

Tel.: 254-0385-22119

Jennifer Oyieke

NARESA

P. O. Box 21361

Nairobi, Kenya

Tel.: 254-2-726644

Fax: 254-2-720413

E-mail: naresa@alphanet.co.ke

Ravai Marindo

Centre for Population Studies

University of Zimbabwe

MP 167, Mount Pleasant

Harare, Zimbabwe

Tel.: 263-4-303211, Ext. 1635

Fax: 263-4-333407

E-mail: ravai@compcentre.uz.ac.zw

Ernest Muyunda

Ndola District Health Management Team

P. O. Box 60672

Ndola, Zambia

Tel./Fax: 260-2-612819

E-mail: emuyunda@zamnet.zm

E-mail:ndodhmt@zamnet.zm
Esther Sakala

Ndola Demonstration Project

Ndola District Health Management Team

P. O. Box 70672

Ndola, Zambia

Tel./Fax: 260-2-612819

E-mail: Esakal@zamnet.zm

E-mail: ndodhmt@zamnet.zm

Annie Banda

Lubuto Clinic

Ndola District Health Management Team

P. O. Box 70672

Ndola, Zambia

Tel.: 260-2-660146

Patchara Rumakom

Population Council

P. O. Box 138, Pratunum

Bangkok 10409

Thailand

E-mail: patchara@popcouncil.th.com

Ruth Nduati

Department of Pediatrics

College of Health Sciences

University of Nairobi

P. O. Box 19676

Nairobi, Kenya

Tel.: 254-2-726644

Fax: 254-2-720413

E-mail: Rnduati@iconnect.co.ke 
Jessie Mbwambo

Muhimbili University

College of Health Sciences

Department of Psychiatry

Off United Nations Road

P. O. Box 65218

Dar es Salaam, Tanzania

Tel./Fax: 255-222-1515137

E-mail: jmbwambo@muchs.ac.tz

Daniel Lukenge

AIDS Information Centre

P. O. Box 10446

Kampala, Uganda

Tel.: 347603

Cell phone: 077-400756

E-mail: dan@aicug.org

E-mail: kiggundu@aicug.org

Paul Waibale

STD/ACP

Ministry of Health

P. O. Box 7272

Kampala, Uganda

Tel.: 340872

Cell phone: 077- 502243

E-mail: vct_moh@afsat.com

Esther Barigye

AIDS Information Centre

P. O. Box 10446

Kampala, Uganda

Tel.: 347603

E-mail: Barigye@aicug.org

Roselida Juma

ANC Clinic

Kenyatta National Hospital

P. O. Box 69745

Nairobi, Kenya

Tel.: 254-2-726300

Cell phone: 072-864750
Christine Muthengi

ANC Clinic

Kenyatta National Hospital

P. O. Box 1139400100 GPO

Nairobi

Tel.: 254-2-726300

Margaret Siwale

MTCT Working Group

P. O. Box 35852

Lusaka, Zambia

Tel.: 260-1-252190

E-mail: Siwalem@coppernet.zm

E-mail: Mtct@zamnet.zm

Chipepo Kankasa

MTCT Working Group

University Teaching Hospital

Lusaka, Zambia

Tel.: 260-1-252118

E-mail: Ckankasa@zamnet.zm

Anne Mutunda

Monze District Health Management Team

P. O. Box 660144

Monze, Zambia

Tel.: 260-026-032-50734/724/700

E-mail: Monzedho@zamnet.zm

Anne Mshanga

MTCT Working Group

P. O. Box 51343

Lusaka, Zambia

Tel.: 260-1-252118

E-mail: Mtct@zamnet.zm

Omondi Ogutu

Department of Obstetrics/Gynecology

Kenyatta National Hospital

Nairobi, Kenya

Tel.: 254-2-726300

Fax: 254-2-719715

E-mail: omogutu@wanainchi.com 


\section{Hgrizons}

Suniti Solomon

YRG CARE

1, Raman Street

T Nagar, Chennai 600017

India

Tel.: 91-44-8264242

Fax: 91-44-8256900

E-mail: yrgcare@vsnl.com

Naomi Rutenberg

Population Council

4301 Connecticut Avenue, N.W.

Suite 280

Washington, DC 20008

Tel.: 202-237-9400

Fax: 202-237-8410

E-mail: nrutenberg@pcdc.org

Sam Kalibala

Population Council

General Accident House

Ralph Bunche Road

P. O. Box 17643

Nairobi, Kenya

Tel.: 254-2-713480

Fax: 254-2-713479

E-mail: skalibala@popcouncil.or.ke

Milka Juma

Population Council

General Accident House

Ralph Bunche Road

P. O. Box 17643

Nairobi, Kenya

Tel.: 254-2-713480

Fax: 254-2-713479
Charles Mwai

Population Council

General Accident House

Ralph Bunche Road

P. O. Box 17643

Nairobi, Kenya

Tel.: 254-2-713480

Fax: 254-2-713479

E-mail: cmwai@popcouncil.or.ke 


\section{Appendix C}

\section{References}

Guay, L.A. et al. 1999. "Intrapartum and neonatal single-dose nevirapine compared with zidovudine for prevention of mother-to-child transmission of HIV-1 in Kampala, Uganda: HIVNET 012 randomised trial," Lancet 354(9181):795-802.

Piwoz, E. et al. 2001. Early Breastfeeding Cessation as an Option for Reducing Postnatal Transmission of HIV in Africa: Issues, Risks and Challenges. Washington, DC: AED.

Shaffer, N. et al., on behalf of the Bangkok Collaborative Perinatal HIV Transmission Study Group. 1999. "Short-course zidovudine for perinatal HIV-1 transmission in Bangkok, Thailand: A randomised controlled trial," Lancet 353(9155):773-80.

Voluntary HIV-1 Counselling and Testing Efficacy Study Group. 2000. "Efficacy of voluntary HIV-1 counselling and testing in reducing sexual transmission of HIV-1 in Kenya, Tanzania, and Trinidad: a randomized trial," Lancet 356(9224):103.

Wiktor, S. et al. "Short-course oral zidovudine for prevention of mother-to-child transmission of HIV-1 in Abidjan, Cote d'Ivoire: a randomized trial," Lancet 353(9155):781. 


\section{Hgrizons}

\section{Appendix D}

\section{Operations Research Priorities}

Ongoing Horizons research focuses on the feasibility, acceptability, impact, and cost of HIV prevention and care in the $\mathrm{ANC} / \mathrm{MCH}$ setting. These studies include many different types of data collection and respondents, including:

- Formative research.

- Process indicators such as numbers of providers trained and IEC activities.

- Routine data on service utilization.

- Client data from a cohort of clients.

- Quality of care through provider observations.

- Measurement of cost to health facility.

Based on consultations with a large and diverse group of partners, the Horizons Program previously identified the following operations research priorities:

- Assess the operational and cost-effectiveness differences between using AZT and nevirapine for PMCT programs.

- Assess the impact of PMCT programs on child survival; this requires long-term follow-up of children and mothers.

- Identify the best strategies for mobilizing communities to support mothers and fathers seeking PMCT services to protect their babies and themselves. Horizons will endeavor to explore the various impacts of community education, community mobilization, and community participation in service delivery on knowledge, norms, stigma, and social support surrounding PMCT.

- Explore how men can become more actively involved in the counseling and care offered to their pregnant partners. Operational issues have made it difficult to reach out of the antenatal clinic setting and bring men in for services. Without such outreach, some men will remain suspicious of the services and act as barriers to their partners' involvement. Horizons proposes exploring the impact of the community involvement interventions cited above on male involvement in PMCT.

- Study the impact of ANC voluntary counseling and testing services on reducing risk among HIV-negative women. VCT offered at dedicated sites has been shown to have a significant impact on reducing the prevalence of unsafe sexual behaviors. Does it have the same or perhaps even greater impact when offered in the context of ANC? It is critical to measure this outcome, because documentation of a significant prevention benefit to HIV-negative women would greatly reduce the cost-to-effectiveness ratio and become a powerful advocacy tool for expansion of PMCT. 
A number of additional operations research questions were proposed at the workshop:

- What is the cost-effectiveness of opt-out strategies for PMCT HIV testing?

- What is the most effective role for community counselors?

- How will the availability of ARVs for treatment of HIV in the mother influence her decisionmaking?

- What is the most effective role of TBAs in PMCT (e.g., pretest counseling, ARVs, infant feeding)?

- What kind of practical tools (e.g., diaries) help women practice exclusive breastfeeding?

- What are the feasibility, acceptability, and effectiveness of maternal nutritional counseling in PMCT programs?

- What are practical strategies (e.g., DOTS, buddy system) to promote adherence to ARV regimens used for PMCT? 


\section{Hgrizons}

Horizons is a global operations research program designed to:

Identify and test potential strategies to improve HIV/AIDS prevention, care, and support programs and service delivery.

Disseminate best practices and utilize findings with a view toward scaling up successful interventions.

For more information, please contact:

Horizons Program, Communications Unit 4301 Connecticut Avenue, NW Suite 280 Washington, DC 20008 USA

Tel: 202-237-9400

Fax: 202-237-8410

Email: horizons@pcdc.org

www.popcouncil.org/horizons/horizons.html

\section{Population Council}

Horizons is implemented by the Population Council in collaboration with - International Center fr Researb on Women (ICPN)

- International HIV/AIDS Alliance

- Program fr Appropriate Technology in Health (PATH)

- Tulane University

· Family Health International (FHI)

· bhns Hopkins Uniersity 